\title{
Current Concepts in the Immunological Diagnosis of H. pylori in Basrah Pediatric Oncology Unit
}

Amer Naes Amer ${ }^{1}$, Janan G. Hassan ${ }^{1}$ and Ihsan E. Al-Saimary ${ }^{2}$

1Department of Pediatrics, College of Medicine University of Basrah, Iraq

2Department of Microbiology - College of Medicine University of Basrah, Iraq

${ }^{*}$ Corresponding author: Dr. Ihsan Edan Al-Saimary (PhD) Assistant Professor, Department of Microbiology, College of Medicine, University of Basrah, Iraq, E-mail: ihsanalsaimary@yahoo.com

Rec date: May 16, 2014; Acc date: Jul 28, 2014; Pub date: Jul 30, 2014

Copyright: (C) 2014 Amer AN, et al. This is an open-access article distributed under the terms of the Creative Commons Attribution License, which permits unrestricted use, distribution, and reproduction in any medium, provided the original author and source are credited.

\section{Abstract}

Objective: The concentration of Immunological markers (IgG, IgM, IgA, C3 and C4) were determine for children with cancer in basrah pediatric oncology unit during 2009.

Methods: A prospective comparative case-control study was carried out over 7 months from $12^{\text {th }}$ of March 2009 to $26^{\text {th }}$ of September 2009, the study included 29 children (20 male and 9 female) with different types of malignancies. Investigations were done for $H$. pylori and one step diagnostic test (which detect the antigen for $H$. pylori) and determine the concentration of (IgG, IgM, IgA, C3, C4).

Results: There is statistically significant higher percentage of patient group having $H$. pylori comparing to control group with $\mathrm{P}<0.05$. Regarding $H$. pylori in relation to immunological status of studied patients, there was a significant association between $H$. pylori and high IgG with a mean (715.01) for $H$. pylori positive patient and mean (553.20) for $H$. pylori negative patient, $P<0.05$ which is statistically significant, this was the same regarding lgA when there was a significant association between $H$. pylori and high IgA with a mean (94.29) for $H$. pylori positive patient and mean (58.54) for $H$. pylori negative patient $P<0.05$ which is statistically significant, also the same regarding $C 4$, there was a significant association between $H$. pylori and low $\mathrm{C} 4$ with a mean (47.31) for $H$. pylori positive patient and mean (79.57) for $H$. pylori negative patient and $P<0.05$ which is statistically significant.

Conclusion: The study evidenced strong relationships between frequency of $H$. pylori and immune compromised Childs according to immunological investigation.

Note: This work is part of thesis submitted by the first author to the scientific council of pediatrics in partial fulfillment for the degree of Fellowship of the Iraqi Board for Medical Specializations in Pediatrics

Keywords: H. pylori; Immunology; Cancer; Children

\section{Introduction}

Helicobacter pylori, or H. pylori, is a spiral-shaped bacterium that is able to grow in the human stomach. Normally, the acidic stomach environment prevents the survival of viruses, bacteria, and other microorganisms [1]. However, H. pylori has evolved to be uniquely suited to thrive in the harsh stomach environment. $H$. pylori bacteria secrete urease, a special enzyme that converts urea to ammonia. Ammonia reduces the acidity of the stomach, making it a more hospitable home for $H$. pylori [2,3]. The ability to survive in the stomach provides $H$. pylori with a useful hiding place. White blood cells that would normally recognize and attack invading bacteria are unable to cross from blood vessels into the stomach lining. Instead, the ineffective white blood cells continue to respond to the site of infection, where they die and release nutrients that feed $H$. pylori $[3,4]$. H. pylori has co-existed with humans for thousands of years. However, because scientists believed the stomach was a sterile organ, this bacterium was not discovered until the 1980s. Some other gut bacteria actually aid their human hosts in the absorption of nutrients and defense against other, more dangerous, microbes [5]. Because $H$. pylori are relatively newly discovered, the complex interactions between this microbe and humans, including its risks and benefits, are still being discovered [6]. More than $50 \%$ of the world's population harbor $H$. pylori in their upper gastrointestinal tract. Infection is more prevalent in developing countries, and incidence is decreasing in western countries [7].

The route of transmission is unknown, although it is known that individuals typically become infected in childhood [6,8]. Diagnosis of infection is usually made by checking for dyspeptic symptoms and by tests which can indicate $H$. pylori infection. One can test noninvasively for $H$. pylori infection with a blood antibody test, stool antigen test, or with the carbon urea breath test (in which the patient drinks 14C- or 13C-labelled urea, which the bacterium metabolizes, producing labelled carbon dioxide that can be detected in the breath) [9]. However, the most reliable method for detecting $H$. pylori infection is a biopsy check during endoscopy with a rapid urease test, histological examination, and microbial culture. There is also a urine ELISA test with a $96 \%$ sensitivity and $79 \%$ specificity. None of the test methods is completely failsafe. Even biopsy is dependent on the location of the biopsy. Blood antibody tests, for example, range from $76 \%$ to $84 \%$ sensitivity. Some drugs can affect $H$. pylori urease activity and give 
false negatives with the urea-based tests $[3,4,10]$. H. pylori colonize the stomach and induce chronic gastritis, a long-lasting inflammation of the stomach. The bacterium persists in the stomach for decades in most people [8].

Most individuals infected by $H$. pylori will never experience clinical symptoms despite having chronic gastritis. Approximately $10-20 \%$ of those colonized by $H$. pylori will ultimately develop gastric and duodenal ulcers. H. pylori infection is also associated with a $1-2 \%$ lifetime risk of stomach cancer and a less than $1 \%$ risk of gastric MALT lymphoma $[9,11]$. It is widely believed that in the absence of treatment, $H$. pylori infection-once established in its gastric nichepersists for life 3. In the elderly, however, it is likely that infection can disappear as the stomach's mucosa becomes increasingly atrophic and inhospitable to colonization. The proportion of acute infections that persist is not known, but several studies that followed the natural history in populations have reported apparent spontaneous elimination $[5,6]$. While $H$. pylori has been disappearing from the stomach of humans, the incidence of the related disorders, acid reflux disease, Barrett's esophagus, and esophageal cancer have been rising dramatically [12]. In 1996, Martin J. Blaser advanced the hypothesis that $H$. pylori has a beneficial effect: by regulating the acidity of the stomach contents, it lowers the impact of regurgitation of gastric acid into the esophagus [13]. The hypothesis is not universally accepted as several randomized controlled trials failed to demonstrate worsening of acid reflux disease symptoms following eradication of $H$. pylori [14]. Nevertheless, Blaser has refined his view to assert that $H$. pylori is a member of the normal flora of the stomach. He postulates that the changes in gastric physiology caused by the loss of $H$. pylori account for the recent increase in incidence of several diseases, including type 2 diabetes, obesity, and asthma. His group has recently shown that $H$. pylori colonization is associated with a lower incidence of childhood asthma $[9,11,14]$. Colonization of the stomach by $H$. pylori results in chronic gastritis, an inflammation of the stomach lining. The severity of the inflammation is likely to underlie $H$. pylori-related diseases [15].

Duodenal and stomach ulcers result when the consequences of inflammation allow the acid and pepsin in the stomach lumen to overwhelm the mechanisms that protect the stomach and duodenal mucosa from these caustic substances [12]. The type of ulcer that develops depends on the location of chronic gastritis, which occurs at the site of $H$. pylori colonization [10]. The acidity within the stomach lumen affects the colonization pattern of $H$. pylori and therefore ultimately determines whether a duodenal or gastric ulcer will form. In people producing large amounts of acid, H. pylori colonizes the antrum of the stomach to avoid the acid-secreting parietal cells located in the corpus (main body) of the stomach [8].

The inflammatory response to the bacteria induces $G$ cells in the antrum to secrete the hormone gastrin, which travels through the bloodstream to the corpus. Gastrin stimulates the parietal cells in the corpus to secrete even more acid into the stomach lumen [15]. Chronically increased gastrin levels eventually cause the number of parietal cells to also increase, further escalating the amount of acid secreted. The increased acid load damages the duodenum, and ulceration may eventually result. In contrast, gastric ulcers are often associated with normal or reduced gastric acid production, suggesting that the mechanisms that protect the gastric mucosa are defective [16]. In these patients $H$. pylori can also colonize the corpus of the stomach, where the acid-secreting parietal cells are located [10]. However chronic inflammation induced by the bacteria causes further reduction of acid production and, eventually, atrophy of the stomach lining, which may lead to gastric ulcer and increases the risk for stomach cancer [17].

Two related mechanisms by which $H$. pylori could promote cancer are under investigation. One mechanism involves the enhanced production of free radicals near $H$. pylori and an increased rate of host cell mutation [18]. The other proposed mechanism has been called a "perigenetic pathway" and involves enhancement of the transformed host cell phenotype by means of alterations in cell proteins such as adhesion proteins $[3,11]$. It has been proposed that $H$. pylori induces inflammation and locally high levels of TNF- $\alpha$ and/or interleukin s6 [8]. According to the proposed perigenetic mechanism, inflammationassociated signaling molecules such as TNF- $\alpha$ can alter gastric epithelial cell adhesion and lead to the dispersion and migration of mutated epithelial cells without the need for additional mutations in tumor suppressor genes such as genes that code for cell adhesion proteins $[15,19]$.

The aims of the present study are to study the frequency of $H$. pylori among patients with cancer and determine of immunological parameters of these patients in comparison with control group.

\section{Materials and Methods}

A prospective comparative case-control study was carried out over 7 months from 12th of March 2009 to 26th of September 2009, the study included 29 children (20 male and 9 female) with different types of malignancies who were admitted to pediatric oncology unit for treatment at Basrah Maternity and children hospital and their age ranged between 18 month to 11 years, and regarded as patient group.

A total of 22 children (12 male and 10 female) who were admitted to basrah Maternity and children Hospital for chest infection and after stabilization, critically ill children were excluded from the study, they were matched for sex and age with patient group and randomly selected as control group.

A special questionnaire was designed for the purpose of the study (Appendix I). The following informations were taken:

- name, age (in month), and sex.

- date of admission.

- Residence of patients.

- type of cancer (ALL, AML, solid tumor),risk group of patient with leukemia.

- clinical features including symptoms and signs: epigastric pain ,dyspepsia, abdominal pain and Vomiting.

- family history of peptic ulcer or endoscopy or recurrent abdominal pain -consanguinity.

- social history including father and mother smoking.

- father and mother education.

Investigations were done for $H$. pylori and one step diagnostic test (which detect the antigen for H.pylori) and determine the concentration of (IgG, IgM, IgA, C3, C4).

One milliliter of serum was taken from the patient for the purpose of immunological study and one step diagnostic test. One step diagnostic test detect the antibodies to $H$. pylori with $95.9 \%$ sensitivity and $89.6 \%$ specificity, but it can be positive in other campylobacters (designed by human company, Belgium). The limitations of this test 
attributed to that the test is used as qualitative rather than quantitative and does not indicate the titer of the antibody in the specimen.

\begin{tabular}{|c|c|c|c|c|}
\hline \multicolumn{2}{|c|}{ Age / gender } & \multirow{2}{*}{$\begin{array}{l}\text { Patient group } \\
\text { No. } \% \\
1551.7 \%\end{array}$} & \multirow{2}{*}{$\begin{array}{l}\text { Control group } \\
1254.5 \%\end{array}$} & \multirow{2}{*}{$\begin{array}{l}\text { P value } \\
>0.05\end{array}$} \\
\hline$>5$ years & \multirow[t]{2}{*}{ Age } & & & \\
\hline$<5$ years & & $1448.3 \%$ & $1045.5 \%$ & \\
\hline \multicolumn{2}{|l|}{ Total } & $29100 \%$ & 22 100\% & \\
\hline Male & \multirow[t]{2}{*}{ Sex } & $2069 \%$ & $1254.5 \%$ & \multirow[t]{2}{*}{$>0.05$} \\
\hline Female & & $931 \%$ & $1045.5 \%$ & \\
\hline \multicolumn{2}{|l|}{ Total } & $29100 \%$ & 22 100\% & \\
\hline
\end{tabular}

Table 1: Distribution of patients and control according to age and sex

A kits of radial immunodifusion plate (Bussero Co., Millano, Italy) were used to determine the concentration of immunoglobulins; IgG and IgM, components of complement C3 and C4 as follows:

Agarose gel containing monoclonal IgG antisera

Agarose gel containing monoclonal IgM antisera

Agarose gel containing monoclonal C3 antisera

Agarose gel containing monoclonal C4 antisera

The wells filled with $5 \mu \mathrm{l}$ of sample (patient's serum) and wait for 5 min. to be completely adsorbing, and incubated the plates for $72 \mathrm{hrs}$ in incubator at $37^{\circ} \dot{\mathrm{C}}$. Plates of IgG, C3 and C4 were read after $18 \mathrm{hrs,}$ while IgM plates after $72 \mathrm{hrs}$., end point of diffusion is indicated by a sharp precipitating ring, which was achieved when incubation time was finished. Readings were done at this time. The diameters of each ring were measured directly by using magnifying lens with micrometers scale. The diameter of the ring was related to antigen concentration and the results were evaluated by using reference standard table (WHO reading, $\mathrm{mg} / \mathrm{dl}$ ) that is packaged with the kit instruction method supplied (Bussero, Milano) Italy.

Statistical analysis was done using SPSS program, data where expressed and comparison of proportions was performed using chisquare test .P value of less than 0.05 was considered as statistically significant, $P$ value of less than 0.01 as highly significant and $P$ value of less than 0.001 as extremely significant.

\section{Results}

Distribution of patients and control according to age and sex s was shown in Table 1.

Regarding age group: $51.7 \%$ of patient was $>5$ years in comparison to $54.5 \%$ of control were $>5$ years so there was no significant difference regarding age group between patient and control.

Regarding sex groups, 29 children were patient group the majority of them were male with male: female ratio equal to 2.2 , while 22 children were control group with male: female ratio equal to 1.2 , with a $\mathrm{p}$ value $>0.05$, so there was no significant difference between the two groups regarding sex.

Results of $H$. pylori antibody testing among patient and control illustrated in Table 2
Among 51 children included in the study 29 children were patients (of them $79.3 \%$ having positive one step diagnostic test), while 22 children were control (of them 54.5 having positive one step diagnostic test).

There is statistically significant higher percentage of patient group having $H$. pylori comparing to control group with a p value $<0.05$.

\begin{tabular}{|l|l|l|l|l|}
\hline One step diagnostic test & patient & control & Total & P value \\
\hline H. pylori + ve & 23 & 12 & 35 & $<0.05$ \\
\cline { 1 - 4 } & $79.3 \%$ & $54.5 \%$ & $68.6 \%$ & \\
H. pylori - ve & 6 & 12 & 16 & \\
\cline { 1 - 4 } & $20.7 \%$ & $54.5 \%$ & $31.4 \%$ & \\
\hline Total & 16 & 22 & 51 & \\
& $100 \%$ & $100 \%$ & $100 \%$ & \\
\hline
\end{tabular}

Table 2: Results of $H$. pylori antibody testing among patient and control

Table 3 shows that there is significant association between $H$. pylori and high IgG, IgA and low $\mathrm{C} 4$ but there is no significant association between $H$. pylori IgM and C3 among patient group $\mathrm{p}>0.05$.

\begin{tabular}{|l|l|l|l|}
\hline Immunoglobulins & $\begin{array}{l}\text { H. pylori -ve } \\
\text { (no. 16) }\end{array}$ & $\begin{array}{l}\text { H. pylori +ve } \\
\text { (no. 13) }\end{array}$ & P value \\
\hline IgG & $715.01 \pm 151.38$ & $553.20 \pm 265.47$ & $<0.05$ \\
\hline IgM & $58.06 \pm 15.67$ & $52.88 \pm 17.83$ & $>0.05$ \\
\hline IgA & $94.29 \pm 22.81$ & $58.54 \pm 28.61$ & $<0.05$ \\
\hline C3 & $101.33 \pm 38.92$ & $138.22 \pm 60.68$ & $>0.05$ \\
\hline C4 & $47.33 \pm 11.05$ & $79.57 \pm 16.78$ & $<0.05$ \\
\hline
\end{tabular}

Table 3: Concentration of immunoglobulin's among immunocompromised children with H.pylori

The Table 4 showing that there is no significant association between $H$. pylori and the type of cancer with a p value $>0.05$ 


\begin{tabular}{|l|l|l|l|l|}
\hline $\begin{array}{l}\text { Types of } \\
\text { H.pylori }\end{array}$ & $\begin{array}{l}\text { Acute lymphocytic } \\
\text { leukemia }\end{array}$ & $\begin{array}{l}\text { Solid } \\
\text { tumor }\end{array}$ & Total & P Value \\
\hline H. pylori + ve & 10 & 3 & 13 & $>0.05$ \\
& $76.9 \%$ & $31.8 \%$ & $100 \%$ & \\
\cline { 1 - 3 } H. pylori - ve & 13 & 3 & 16 & \\
& $81.3 \%$ & $18.7 \%$ & $100 \%$ & \\
\hline
\end{tabular}

Table 4: Relation between types of $H$. pylori and types of malignancy

\section{Discussion}

Helicobacter pylori represents one of the most common and medically prominent infection worldwide many research done regarding $H$. pylori but only small number of researches done about the relation of $H$. pylori and childhood cancer including acute lymphocytic leukemia and solid tumor [20].

Regarding $H$. pylori in relation to immunological status of studied patients, there was a significant association between $H$. pylori and high IgG with a mean (715.01) for $H$. pylori positive patient and mean (553.20) for $H$. pylori negative patient and $\mathrm{p}$ value less than 0.05 which is statistically significant, this was the same regarding IgA when there was a significant association between $H$. pylori and high IgA with a mean (94.29) for $H$. pylori positive patient and mean (58.54) for $H$. pylori negative patient and $\mathrm{p}$ value less than 0.05 which is statistically significant, also the same regarding $\mathrm{C} 4$, there was a significant association between $H$. pylori and low $\mathrm{C} 4$ with a mean (47.31) for $H$. pylori positive patient and mean (79.57) for $H$. pylori negative patient and $\mathrm{p}$ value less than 0.05 which is statistically significant.

Seroprevalence of $H$. pylori is low in patients receiving organ transplants, possibly due to the use of antibiotics [21], suggesting that systemic administration of antibiotics eradicates H.pylori, and most of the patients basrah hospital had received antibiotics in their course of treatment as well so the false negatives occur in immunocompromised patients. Nonetheless, the sensitivity of serological assays is poor in children. The strains in Asia are different from those that are circulating in the rest of the world [22]. The mean antibody levels in young children are significantly lower than in older children and adults and these age-related standard values have not been established for children [23].

This supports the hypothesis that in developing countries the acquisition of $H$. pylori infection can occur in early childhood [24].

\section{References}

1. Parsonnet J, Hansen S, Rodriguez L, Gelb AB, Warnke RA, et al. (1994) Helicobacter pylori infection and gastric lymphoma. N Engl J Med 330: 1267-1271.

2. Nutpho P, Ukarapol N (2006) Helicobacter pylori and immunocompromised children. Emerg Infect Dis 12: 171-172.

3. Hardikar W, Davidson PM, Cameron DJS, Gilbert GL, Campbell PE (2008) Helicobacter pylori infection in children. journal of gastroenterology and hepatology 5: 450-454.

4. Mohammad MA, Hussein L, Coward A, Jackson SJ (2006) Prevalence of Helicobacter Pylori infection among Egyptian children :impact of social background and effect on growth. Public Health Nutr 11: 230-236.
5. Replogle ML, Glaser SL, Hiatt RA, Parsonnet J (1995) Biologic Sex as a Risk Factor for Helicobacter pylori Infection in Healthy Young Adults. Am J Epidemiol 142: 856-863.

6. Graham DY, Malaty HM, Evans DG, Evans DJ Jr, Klein PD, et al. (1991) Epidemiology of Helicobacter pylori in an asymptomatic population in the United States. Effect of age, race, and socioeconomic status. Gastroenterology 100: 1495-1501.

7. Dore MP, Fastame L, Tocco A, Negrini R, Delitala G (2005) Immunity Markers in Patients with Helicobacter pylori Infection: Effect of Eradication. Helicobacter 10: 391-397.

8. Vakil N1, Fennerty B (1996) The economics of eradicating Helicobacter pylori infection in duodenal ulcer disease. Am J Med 100: 60S-63S.

9. Yamaoka Y (2008) Helicobacter pylori: Molecular Genetics and Cellular Biology. Caister Academic Pr.

10. Brown LM (2000) Helicobacter pylori: epidemiology and routes of transmission. Epidemiol Rev 22: 283-297.

11. Stark RM, Gerwig GJ, Pitman RS, Potts LF, Williams NA, et al. (1999) Biofilm formation by Helicobacter pylori. Lett Appl Microbiol 28: 121-126.

12. Chan WY, Hui PK, Leung KM, Chow J, Kwok F, et al. (1994) Coccoid forms of Helicobacter pylori in the human stomach. Am J Clin Pathol 102: 503-507.

13. Liu ZF, Chen CY, Tang W, Zhang JY, Gong YQ, et al. (2006) Geneexpression profiles in gastric epithelial cells stimulated with spiral and coccoid Helicobacter pylori. J Med Microbiol 55: 1009-1015.

14. Kusters JG, van Vliet AH, Kuipers EJ (2006) Pathogenesis of Helicobacter pylori infection. Clin Microbiol Rev 19: 449-490.

15. Josenhans C, Eaton KA, Thevenot T, Suerbaum S (2000) Switching of flagellar motility in Helicobacter pylori by reversible length variation of a short homopolymeric sequence repeat in fliP, a gene encoding a basal body protein. Infect Immun 68: 4598-603.

16. Rust M, Schweinitzer T, Josenhans C (2008) Helicobacter Flagella, Motility and Chemotaxis. in Yamaoka Y. Helicobacter pylori: Molecular Genetics and Cellular Biology. Caister Academic Press 34: 433-441.

17. Baldwin DN, Shepherd B, Kraemer P, Hall MK, Sycuro LK, et al. (2007) Identification of Helicobacter pylori genes that contribute to stomach colonization. Infect Immun 75: 1005-1016.

18. Broutet N, Marais A, Lamouliatte H, de Mascarel A, Samoyeau R, et al. (2001) cagA Status and eradication treatment outcome of antiHelicobacter pylori triple therapies in patients with nonulcer dyspepsia. J Clin Microbiol 39: 1319-1322.

19. Ottemann KM, Lowenthal AC (2002) Helicobacter pylori uses motility for initial colonization and to attain robust infection. Infect Immun 70: 1984-1990.

20. Mansour-Ghanaei F, Mashhour MY, Joukar F, Sedigh M, Bagher-Zadeh AH, et al. (2009) Prevalence of Helicobacter Pylori Infection among children in Rasht, Northern Iran. Middle East Digest Dis 1: 84-88.

21. Nguyen BV, Nguyen KG, Phung CD, Kremp O, Kalach N, et al. (2006) Prevalence of and factors associated with Helicobacter pylori infection in children in the north of Vietnam. Am J Trop Med Hyg 74: 536-539.

22. Malaty HM (2007) Epidemiology of Helicobacter pylori infection. Best Pract Res Clin Gastroenterol 21: 205-214.

23. Suarez G, Reyes VE, Beswick EJ (2006) Immune response to H. pylori. World J Gastroenterol 12: 5593-5598.

24. Jiménez-Guerra F, Shetty P, Kurpad A (2000) Prevalence of and risk factors for helicobacter pylori infection in school children in mexico. Ann Epidemiol 10: 474. 